Discussion Paper No. 1025

\title{
THE SUPERIOR PEER \\ IMPROVES ME: \\ EVIDENCE FROM SWIMMING DATA
}

Shoko Yamane
Ryohei Hayashi

March 2018

The Institute of Social and Economic Research

Osaka University

6-1 Mihogaoka, Ibaraki, Osaka 567-0047, Japan 


\title{
The Superior Peer Improves Me: Evidence from Swimming Data
}

\author{
Shoko Yamane ${ }^{\dagger}$ and Ryohei Hayashi ${ }^{\ddagger}$
}

March 2018

\begin{abstract}
This study examined the peer effects of newcomer on the performance of existing members of teams, based on comparing the performances of swimming team members before and after the arrival of a newcomer. The identification strategy was similar to a natural experimental setting. This study found that the performance of an existing member of a team improves when a newcomer joins the team and that this effect is larger when the newcomer is a superior to the original team members.
\end{abstract}

Keywords: Peer effect, Sports data

JEL classification: D62, L83

\footnotetext{
$\dagger$ Faculty of Economics, Kindai University, 3-4-1 Kowakae, Higashi-Osaka, Osaka, 577-8502, JAPAN, E-mail: syamane@kindai.ac.jp, Tel: +81-6-6721-2332

\$ School of Political Science and Economics, Tokai University

We thank Hiroki Shimoi and Tatsuki Miyata for their help in data cleansing. We are deeply grateful to Fumio Ohtake. An earlier version of this paper was presented at the Kyoto Summer Workshop on Applied Economics, Kansai Labor Seminar, and the CEE and RISS Seminar Series on Experimental Economics. We would like to express our gratitude to all seminar participants for their valuable comments. This work was supported by JSPS KAKENHI Grant Number JP15K17029, and a grant from the MEXT Joint Usage/ Research Center at the Institute of Social and Economic Research, Osaka University.
} 


\section{Introduction}

People spend a large amount of their lives in classrooms and workplaces where their classmates and colleagues are assumed to influence them in many ways: for instance, most people have had the experience of starting something new because of a colleague's example or aspiring to something as a result of a classmate's influence. Few studies, however, have measured such long-term social effects. Several interesting topics in this field have remained unexplored. For example, does an individual with greater skill enhance or inhibit his/her peers? Is the influence of a talented individual limited to those around him/her or does it expand to cover all members? This study attempts to answer these questions.

The social effects from classmates and colleagues would have two pathways, namely, learning effect and motivation effect. In the learning effect, learning a better way from others is effective in improving one's performance. Motivation effect means that the existence of peers itself enhances one's performance. In either pathway, the performances of others influence one's productivity. This externality is called "peer effect" in economics, studied extensively in the areas of educational or labor economics.

Examining peer effects in a real-world setting requires data on the performance of each individual and those of peers assigned randomly. If the peer assignment is non-random, the estimated peer effect becomes biased because the error term is correlated with the characteristics of the peers ${ }^{1}$. Further, to reveal peer effects, these effects must not be reflected and overlapped. Social effects are always endogenous; in other words, a person simultaneously influences and is influenced by a group. This endogeneity makes it difficult to estimate the causal impact of peer effects, as Manski (1993) discussed. It is not easy to find micro data that meet these conditions, and more so for individual panel data. It has resulted in a scarcity of empirical literature on long-term peer effects.

To address these identification problems, research can focus on newcomers. For original members, the appearance of a newcomer is exogeneous and may be characterized as a random shock ${ }^{2}$. Therefore, by comparing performance before and after transfer, the peer effects by a newcomer could be revealed clearly ${ }^{3}$. The comparison requires that transfer timings on the panel data containing the individuals' and their peers' performances be identified. The appropriate empirical data are hard to find; however, we found that this gap could be bridged by swimming data.

${ }^{1}$ Other identification problems, such as common shock, require resolution. Sacerdote (2011) summarized these problems and the methods for their resolution.

2 Although the newcomer's performance itself seems open to modification, the transfer could not be exogenous for a transfer. For example, they might transfer schools because they were in trouble with the teacher or classmates, or because their grades were not improving. Therefore, the changes in newcomers' performances were not focused upon.

3 The impact of transference may be examined by comparing the teams with respect to the presence and absence of transfers. However, the swimming teams that had never imported or exported members are biased. For example, such teams could be weak, small, have decided to be closed, or isolated. Therefore, this mode of comparison was not adopted. 
The swimming data in this study, collected from an open online database, include nine-year individual panel data that comprise the records and team names for each competition and swimmer. In tracking the changes of one team, transfer swimmers need to be identified, along with their transfer timings to new teams. Our data also include the characteristics of the transferees (e.g., school, age, gender, personal best record, and previous team's name). As such, differences in the impact from superior and inferior peers can be revealed. Another advantage is that swimming records provide a constant and objective index of individual performance without any room for luck. In contrast with using examination scores, for instance, the examination difficulty would be controlled, but this control is difficult to achieve. Meanwhile, swimming records are free from this problem and are evaluated by the same standards regardless of time and place. Measurement errors can be ignored because swimming records in official competitions are measured electronically. In addition, to swim fast is a common aim for every swimmer, compared with the complex aims related to school education: not only to get high examination scores but to increase scholastic abilities. Swimming is a sport of speed, and every swimmer in the competition intends to swim as fast as he/she can.

Swimming is a highly popular after-school activity in Japan. In a survey by Recruit Life Style (2015), swimming accounted for $43.7 \%$ of all after-school culture lessons among elementary school students $^{4}$. In Japan, swimming is a compulsory activity from elementary to high school. Most parents send their children to swimming clubs to prevent them from developing an inferiority complex, so there are many swimming clubs, both large and small, all across Japan and most children attend them once or twice a week. As swimmers spend the most time with their teammates, there is a mutual exchange and learning of better techniques. They are also mutually motivated in friendly rivalry.

In the context of peer effect, especially focusing on learning effect, many scholars have conducted studies. Burke and Sass (2013) and Cooley (2009) indicated that classmates influence one another using test scores. While most studies did indicate a significant effect from classmates, Zimmerman (2003) and Hayashi (2016) denied the influences of roommates, who spend more time with one another than classmates, on academic achievements. Both studies used randomly assigned roommates. In the classroom, an important question is how the spillover works. Hoxby and Weingarth (2005) summarized a number of spillover models, such as the Bad Apple model, which states that the presence of a low-ability student harms and "spoils" many other students. In the Shining Light model, a high-ability student improves all others. Further, the Invidious Comparison model suggests that high-ability students are negatively affect the performances of lower-ranking students, whereas the Boutique model means that students' performances are enhanced when they

\footnotetext{
${ }^{4}$ Respondents to this survey were 927 mothers of elementary school kids who attended after-school lessons.
} 
are surrounded by others like themselves. The present work can suggest which spillover models are observed in the afterschool club activity among elementary and junior high school students. The spillover effect has been reported in the workplace as well. For example, Kato and Shu (2016) collected rejection rates as measurements of performance at a large textile firm in China, and noted a spillover effect from high-ability to low-ability weavers, but not vice versa.

Some economic studies have focused on the effects of transfers. Moser et al. (2014) used Jewish émigrés from Nazi Germany to the U.S. and found that the number of patents in fields that accepted émigrés increased by $31 \%$. Contrary to this, from similar studies focused on exporters, Azoulay et al. (2010) showed that when so-called academic superstars died, the publications of their collaborators declined by $5 \%$ to $8 \%$. Waldinger (2012) found no influence by local peers among researchers, using data on the dismissal of scientists in Nazi Germany.

Finally, scholars have investigated peer effects using sports data. Gneezy and Rustichini (2004) revealed, using elementary school running data, that the existence of competitors improves boys' performances but not girls'. Yamane and Hayashi (2015) reported a relatively clean test of peer effects using swimming data and revealed that peers influence individuals' performance. They also found that being chased improves one's performance, and that observability is an important determinant of peer effects. Both studies used data from short-term competitions, which cannot provide information on learning effects. Other studies have demonstrated the influence of much superior peers, which might be called the superstar effect. Brown (2011) investigated the effect of the superstar, Tiger Woods, on his peers using PGA tournament data. He found that the existence of a superstar diminished the performance of competitors. Gould and Kaplan (2011), using baseball data, showed the effects of Jose Canseco, a star baseball player later arrested for using steroids: the number of homeruns scored by Canseco's team significantly increased after playing with Canseco. They concluded that Canseco taught his teammates how to play well but also influenced them on how to use steroids, which is a negative learning effect.

While numerous studies already exist related to peer effects, the present work may be the first to examine and demonstrate clearly the learning and motivation effects from peers using exogenous shock. The rest of this paper is organized as follows: Section 2 presents the dataset and estimation model, the estimation results are explained in Section 3 and, finally, the discussion and conclusion are given in Section 4.

\section{Methods}

\subsection{Data source}

We have collected data from Swim-Record.com (http://www.swim-record.com/index.html), which is the official website of the Japan Swimming Federation (JSF). The site contains records from approximately 1,500 official competitions, which are held by every JSF member organization in 
each prefecture. Members are obliged to release all official JSF competition records to the public. Because the official records contained only JSF-registered swimmers in competitions that are governed by international rules, the data excluded unofficial records (e.g., citizens' competitions). The database covered records of swimming competitions for individuals, from first-year elementary to university students and working adults, from April 1, 2007 to March 31, 2015.

\subsection{Dataset}

First, transfer swimmers were identified. A transfer swimmer was defined as an individual whose team name changed ${ }^{6}$. We only considered transfers in which the time gap between the last record with the previous team and the first record with the new team was within one year, and where those concerned had records of more than one year in both their former and later teams. This was to eliminate possible errors whereby a swimmer could be misidentified as a transfer having participated in a competition with another team just once. In this process, 304 transferred swimmers were identified in our dataset.

Second, the records of all members who belonged to the teams that accepted the transfer swimmers were extracted. If there were many imports, the effects of newcomers would overlap, and thus the peer effect could not be determined clearly. Therefore, the teams that accepted one transfer only once in our dataset or that had a time gap between each transfer longer than one year were used. The assumption that a newcomer is no longer a newcomer when one year has passed was examined in Section 3.3, by changing the data analysis, using two periods: half-year and two-year gaps.

So far, the records included all swimming styles and race types ${ }^{7}$. At this point, we kept only the 50-meter freestyle records in short-course pools, because this category is held year-round and has the largest number of participants ${ }^{8}$. In addition, the data on adults and university students were excluded, because they often belong to more than one team in Japan. It is also common practice for college

\footnotetext{
5 The Japanese school year begins in April.

${ }^{6}$ Several inconsistencies in the spelling of team names were observed, because they were registered manually for each competition. For example, variations of the team name "Hayashi Swimming Club" included "Hayashi SC" or "HSC." However, the "Hayashi Swimming Center" could also be abbreviated as "HSC." In cases such as this, distinguishing between the two was a challenge. In addition, the Japanese language uses four character types, namely, Kanji, Hiragana, Katakana, and Romaji, which further complicated the differentiation. Therefore, other information, such as physical addresses and member names of a team before and after competitions, was checked to correct the team names.

7 There are four swimming styles, namely, freestyle, butterfly, breast stroke, and backstroke. Swimming also has two types of races. The first is "finals," in which only swimmers who survive their heats swim in the final round. This system is used in the Olympic Games. The second type is "timed finals," which has no final round. In timed finals, all players swim only once, and each swimmer's time in the heats determines their final rank.

${ }^{8}$ There are two pool sizes in official swimming competition. The short-course means a 25 -meter pool and long-course is a 50-meter pool. Swimming is a sports for all season in Japan, and short-course races are the most common throughout the year.
} 
students to nominally belong to a university swimming club in whose name they participate in the meets but to actually continue training with their original club. Thus, only those on high-school students and below were used.

The data on meets, which can only be participated in under the school's name as a member of the school's club, were excluded. However, this may have ignored the influences by peers of the school club activities. We cannot identify one's peer of school club activity completely because not all swimmers are participated to the meets with school name. Although the presence of a 'superstar' as a peer of school club could have an especially strong influence on others, there are some swimmers who are more influenced by peers in school club activities than peers from the extracurricular swimming team, whereas other swimmers are not. This is a limitation of the dataset, however, it should not be considered as harming our results.

To summarize, our dataset consists of unbalanced panel data of 50-meter freestyle records in short-course pools from 2007 to 2015. It contained data of first-year elementary school to high school students. Note that the time indicator is each meet, which are held almost every weekend. Thus, there were 77,798 records of 6,258 individuals (3,264 males and 2,994 females) with 304 transfers (153 males and 151 females). These records were associated with their personal best record at that time, gender, school age, and the date when the transfer took place.

\subsection{Estimation Model}

The estimation model used is as follows:

$$
\text { Record }_{i m t}=\alpha_{i m}+\beta_{1} \text { After }_{i m t}+\beta_{2} \text { Best }_{i m t}+\beta_{3} \text { Date }_{i m t}+\varepsilon_{\text {imt }}
$$

where $\operatorname{Record}_{i m t}$ denotes the record of swimmer $i$ of team $m$ at competition $t$. Again, note that the time indicator is each meet. After is a key variable, which takes a value of 1 after a newcomer joins his/her swimming team, and is otherwise 0. Best refers to swimmer $i$ 's personal best records at $t$. To obtain the Best value, all previous records of each swimmer were collected. This model was estimated with fixed effects for $i$ using robust standard errors clustered by team. The individual characteristics such as gender and school age are included in the fixed effect. If the transfer of a newcomer did not affect a swimmer's performance, the coefficient of After is not significant. Date is also a control variable, because swimmers become faster as they develop. Date contains a serial value in which the date January 1, 1900 takes the value of 1, the date January 2, 1900 takes 2, and so on. The variable Date squared is divided by $1,000,000$, because the digit number is too large. We adopted the fixed effect model and individual characteristics such as age and gender are included in the fixed effect.

To consider the characteristics of a newcomer, a cross-term was employed in the regression model:

$$
\text { Record }_{\text {imt }}=\alpha_{i m}+\gamma_{1} \text { After }_{\text {imt }}+\gamma_{2} \text { After } * \text { Fast }_{\text {imt }}+\gamma_{3} \text { Best }_{\text {imt }}+\gamma_{4} \text { Date }_{i m t}+\varepsilon_{\text {imt }}
$$

where After*Fast denotes the cross-term of After and Fast newcomer dummy variables. The After 
transfer dummy variable equals 1 after a newcomer joins his/her swimming team. The Fast newcomer dummy variable equals 1 when the newcomer's personal best is faster than one's personal best at the timing of transfer. Using this cross-term, the effect of a fast or a slow newcomer could be distinguished.

\section{Results}

\subsection{Descriptive statistics}

We begin by presenting the descriptive statistics of key variables. The sample comprised 304 transferred swimmers (153 males and 151 females). As shown in Table 1, the mean personal bests of a swimmer and a newcomer were 33.22 and 32.50 seconds, respectively; their mean school ages were 5.6 and 6.03 years, respectively; note that the lower value of a personal record indicate a better performance. School age refers to educational stage, such that 1 means first-grade elementary school; 7, first-grade middle school; and 12, third-grade high school.

Table 1: Descriptive statistics of subjects

\begin{tabular}{lrrrr}
\hline \multicolumn{1}{c}{ Variable } & \multicolumn{1}{c}{ Mean } & Std. Dev. & \multicolumn{1}{c}{ Min } & \multicolumn{1}{c}{ Max } \\
\hline Own record & 32.76 & 4.38 & 22.83 & 78.82 \\
Own personal best record & 33.22 & 4.93 & 22.92 & 85.03 \\
Own school age & 5.60 & 2.14 & 1.00 & 12.00 \\
A newcomer's personal best record & 32.50 & 3.56 & 23.35 & 51.95 \\
A newcomer's school age & 6.03 & 1.83 & 3.00 & 12.00 \\
After transfer dummy & 0.50 & 0.50 & 0.00 & 1.00 \\
Fast newcomer dummy & 0.53 & 0.50 & 0.00 & 1.00 \\
\hline
\end{tabular}

\subsection{Regression results}

Table 2 shows the main results of the regression analysis. The findings showed that the coefficient of After dummy is negatively significant, indicating that a swimmer's performance improves after a newcomer joins the team in specification (1). In addition, the estimation result of specification (2) shows the cross-term of fast newcomer and after dummy variables are negatively significant, indicating that the faster the newcomer is, the greater the improvement in the performance of his/her teammates. The null hypothesis, which stated that the sum of the After dummy and cross-term is zero, was rejected $(\mathrm{F}(1,278)=29.97, p<.001)$. 
Table 2: Results of the regression analysis on the effect of a newcomer

\begin{tabular}{lcccc}
\hline \multirow{2}{*}{ Variables } & \multicolumn{2}{c}{ Specification (1) } & \multicolumn{2}{c}{ Specification (2) } \\
& Coef. & Std. Err & Coef. & Std. Err \\
\hline After transfer dummy & -0.072 & {$[0.024]^{* *}$} & 0.085 & {$[0.025]^{* *}$} \\
After dummy * Fast newcomer dummy & & & -0.299 & {$[0.048]^{* *}$} \\
Own personal best record & 0.638 & {$[0.015]^{* *}$} & 0.634 & {$[0.015]^{* *}$} \\
Date & -0.001 & {$[0.001]$} & -0.001 & {$[0.001]$} \\
Date squared & 0.006 & {$[0.025]$} & -0.002 & {$[0.025]$} \\
Constant & 37.311 & {$[9.320]^{* *}$} & 36.231 & {$[9.442]^{* *}$} \\
\hline Observations & \multicolumn{5}{c}{77,798} \\
Number of subjects & \multicolumn{5}{c}{6,258} & 77,731 \\
\hline & \multicolumn{5}{c}{ Note: ** $1 \%, * 5 \%$ significance }
\end{tabular}

\subsection{Robustness checks}

Four tests were performed to check the robustness of our analysis. First, in the placebo test, transfer swimmers, who were different from actual transfers of each swimmer, were randomly combined. For example, swimmer A in team B, which received transfer C on January 1, 2016 whose individual best record was 30 seconds, was combined with a counterfactual importer $\mathrm{D}$, whose transfer date was October 30, 2015 and best record was 25 seconds. The dummy variable for after transfer was created in this dataset, and examined using the regression specification (1) in Table 2. After conducting 1,000 placebo trials, the After dummy variable was found to be insignificant in $94 \%$ of trials.

The exogeneity of the transfer was examined next. Transferring to a swimming team could include endogenous factors: other transferred swimmers might have changed their team because they have friends in a new team; alternatively, their records did not improve or the teaching method of the previous team did not suit them. To exclude the endogenous factors and treat the transfer as a clearly exogenous factor, newcomers who transferred to another swimming team in a different prefecture were used in the analysis. As transfers between prefectures were often attributed to relocation of the swimmer, the data were assumed to exclude those transfers that involved a swimmer's problem with the team, teammate, or coach. Of the 304 transfer swimmers, 67 came from another prefecture, covering 19,342 records, which were used to investigate the influence of inter-prefecture newcomers. Table 3 shows the results of the analysis on newcomers from another prefecture. The after-transfer dummy variable was found not significant but marginally significant at a $5 \%$ level, and the cross-term significantly negative. As these results are consistent with those in Table 2, there is little endogeneity in the transfer of swimmers. 
Table 3: Results of the regression analysis on newcomers from another prefecture

\begin{tabular}{|c|c|c|c|c|}
\hline \multirow[b]{2}{*}{ Variables } & \multicolumn{2}{|c|}{ Specification (1) } & \multicolumn{2}{|c|}{ Specification (2) } \\
\hline & Coef. & Std. Err & Coef. & Std. Err \\
\hline After transfer dummy & -0.102 & {$[0.054]$} & 0.046 & {$[0.051]$} \\
\hline After dummy * Fast newcomer dummy & & & -0.279 & {$[0.090]^{* *}$} \\
\hline Own personal best record & 0.605 & {$[0.027]^{* *}$} & 0.601 & {$[0.027]^{* *}$} \\
\hline Date & -0.003 & {$[0.002]$} & -0.003 & [0.002] \\
\hline Date squared & 0.04 & [0.049] & 0.033 & {$[0.050]$} \\
\hline Constant & 51.091 & {$[17.926]^{* *}$} & 50.481 & {$[18.190]^{* *}$} \\
\hline Observations & & 19,342 & & 19,328 \\
\hline Number of subjects & & 1,626 & & 1,626 \\
\hline \multicolumn{3}{|c|}{ H0: After dummy + After dummy $*$ Fast newcomer dummy $=0$} & \multicolumn{2}{|c|}{$\begin{array}{c}F(1,66)=9.08 \\
\text { Prob }>F=0.004\end{array}$} \\
\hline
\end{tabular}

Note: $* * 1 \%, * 5 \%$ significance.

Third, the period within which the influences of transfer disappeared were investigated. As noted in Section 2, this study considered that a newcomer was no longer a newcomer once a year had passed, and that therefore peer effects do not overlap if there was a gap longer than one year between two transfers. To examine whether this assumption was correct, two datasets were used. In the two-year gap dataset, the teams that accepted one transfer only once in our dataset, or the teams that had a time gap between each transfer longer than two years were used. Meanwhile, in the one-year gap dataset, the teams that accepted one transfer only once in our dataset, or the teams that had a time gap between each transfer longer than half a year, were used. There were 130 and 599 transfer swimmers in the two-year and half-year gap datasets, respectively. The estimation results shown in Table 4 are almost consistent with those of Table 2. 
Table 4: Results of the regression analysis using the two-year ad half-year gap datasets

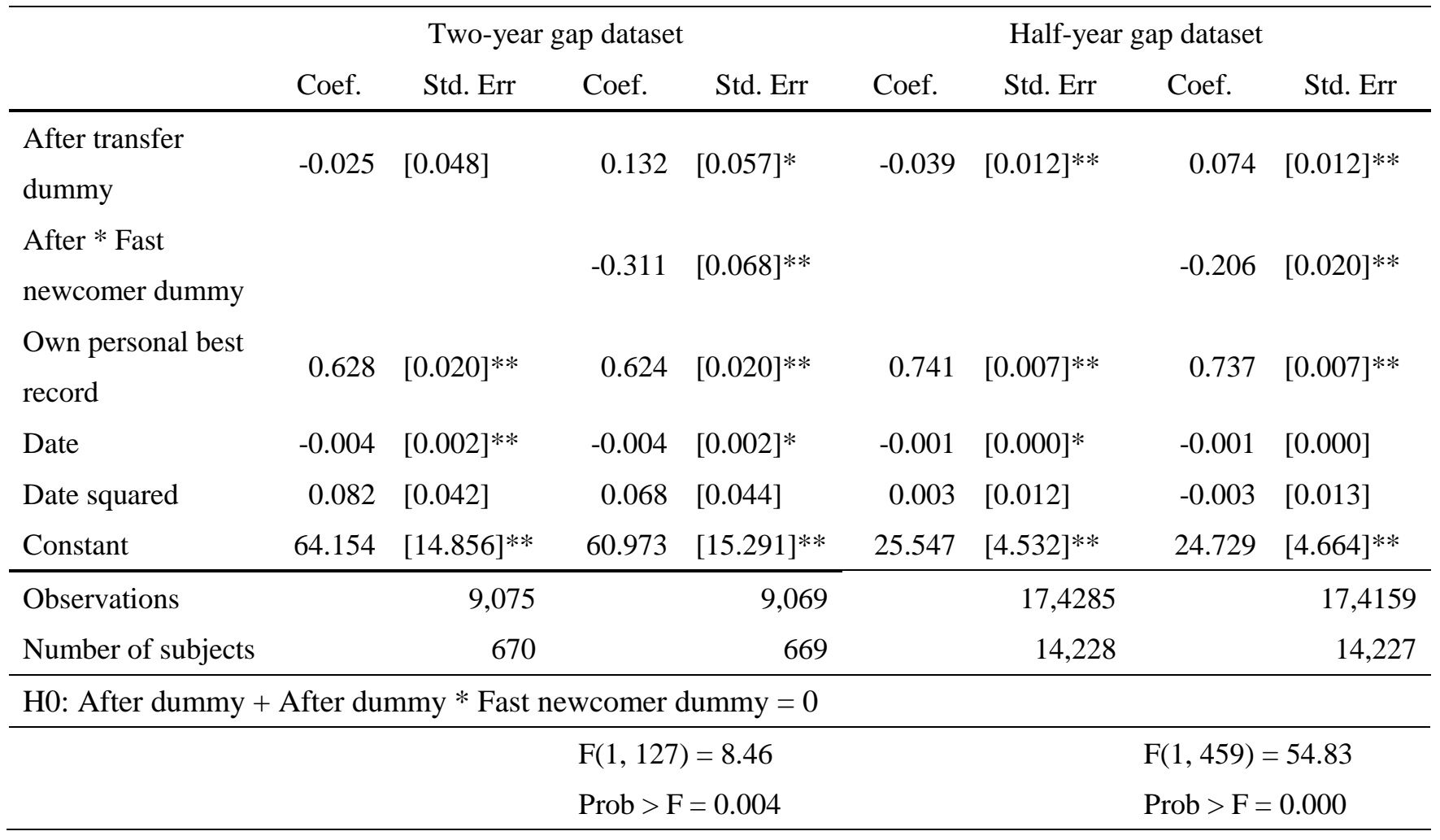

Note: $* * 1 \%, * 5 \%$ significance.

Finally, the effect of swimmers leaving a team was examined. As this could disrupt the process of analyzing the effect of a newcomer, teams that lost swimmers during the year were excluded from the analysis. The effect was to give a 'super-clean' body of data as there was only one possible variable - the arrival of a single newcomer - to be taken into consideration. There were 75 transfer swimmers (42 males and 33 females). The estimation results shown in Table 5 are similar to those in Table 2.

As results had not changed following all four robustness checks, it can therefore be concluded that a newcomer to a swimming team improves other swimmers' performances, and this effect is larger when the newcomer is a better swimmer than the original team members. These findings indicate a positive peer effect among teammates. 
Table 5: Results of the regression analysis excluding teams losing members

\begin{tabular}{lcccc}
\hline & \multicolumn{2}{c}{ Specification (1) } & \multicolumn{2}{c}{ Specification (2) } \\
Variables & Coef. & Std. Err & Coef. & \multicolumn{1}{c}{ Std. Err } \\
\hline After transfer dummy & -0.149 & {$[0.067]^{*}$} & -0.018 & {$[0.041]$} \\
After dummy * Fast newcomer dummy & & & -0.217 & {$[0.086]^{*}$} \\
Own personal best record & 0.608 & {$[0.021]^{* *}$} & 0.607 & {$[0.021]^{* *}$} \\
Date & -0.004 & {$[0.002]$} & -0.004 & {$[0.002]$} \\
Date squared & 0.076 & {$[0.064]$} & 0.072 & {$[0.064]$} \\
Constant & 62.813 & {$[23.679]^{* *}$} & 62.334 & {$[23.414]^{* *}$} \\
\hline Observations & & 11,757 & & 11,740 \\
Number of subjects & & 1,176 & & 1,176 \\
\hline \multicolumn{2}{c}{ H0: After dummy + After dummy * Fast newcomer dummy $=0$} & & \multicolumn{2}{c}{$\mathrm{F}(1,71)=6.12$} \\
\end{tabular}

Note: $* * 1 \%, * 5 \%$ significance.

\subsection{Most effective peer effect}

In this section, the focus was on the detailed characteristics of the newcomers and whether their influence on peers is limited to those immediately around them or expand to all members of the team. Most studies on social comparison have considered the resemblance of attributes as important. For example, as noted in the Introduction, the "boutique model" states that students are enhanced when they are surrounded by others like themselves. Similarly, it is often considered that people compare themselves with "people like me" in the context of happiness and social comparisons (Clark, Frijters, and Shields, 2008). To investigate whether such a similarity is a determinant of the impact of peer effect on teammates, similarities between personal best records and demographic factors, such as gender and school age, were considered. First, similar-record newcomer was defined as a newcomer whose personal best was within $5 \%$ of a team-mate's'. For example, a newcomer whose personal best is 30 seconds is considered a similar-record newcomer for swimmers whose personal bests are between 28.5 and 31.5 seconds. A dummy variable, which takes a value of 1 after a similar-record newcomer joins his/her swimming team and is otherwise 0, was created. Then its cross-term was used with the After dummy in regressions. Based on the findings of Table 6, the cross-term is not significant, whereas the After dummy variable is negatively significant, ${ }^{10}$ suggesting that the

\footnotetext{
${ }^{9}$ Five percent was adopted as threshold because a one-second difference between 24 and 25 seconds is not the same as a one-second difference between 49 and 50 seconds. Thus, relative instead of absolute difference was used. However, for newcomers whose personal best was within one second of their team-mates', the significance of the estimated coefficients did not change.

10 The null hypothesis on cross-term, which states that the sum of the After and similar-record
} 
similarity of records does not affect the impact of peer effect.

In addition, similarities of gender and school age were examined. A dummy variable, which takes the value of 1 if a swimmer and a transfer swimmer have the same gender and is otherwise 0 , was created. Then its cross-term among after-transfer dummy variables was used in the estimation. Similarly, near-school-age newcomer takes the value of 1 if the difference in school age between a swimmer and a newcomer is within a year, and is otherwise 0. For example, a newcomer at sixth grade is a near-school-age newcomer for a swimmer from the fifth to seventh grade. The findings showed that similarity of gender does not change the impact of peer effect, whereas the closeness of school age significantly increased the effect. As Table 6 shows, only the cross-term between near-school-age newcomer and the after transfer dummy variables is negatively significant.

Table 6: Impact of a newcomer who has similar attributions as existing swimmers

\begin{tabular}{lcccccc}
\hline \multicolumn{1}{c}{ Variables } & Coef. & Std. Err & Coef. & Std. Err & Coef. & Std. Err \\
\hline After-transfer dummy & -0.062 & {$[0.026]^{*}$} & -0.071 & {$[0.031]^{*}$} & -0.061 & {$[0.031]$} \\
After dummy * & & & & & & \\
Similar-record newcomer & -0.040 & {$[0.020]$} & & & -0.039 & {$[0.020]$} \\
dummy & & & & & & \\
After dummy * & & & & & & \\
Near-school-age dummy & & & -0.168 & {$[0.066]^{*}$} & -0.168 & {$[0.067]^{*}$} \\
After dummy * & & & & & & \\
Same-gender dummy & & & 0.014 & {$[0.034]$} & 0.014 & {$[0.034]$} \\
Own personal best record & 0.638 & {$[0.015]^{* *}$} & 0.638 & {$[0.015]^{* *}$} & 0.638 & {$[0.015]^{* *}$} \\
Date & -0.001 & {$[0.001]$} & -0.001 & {$[0.001]$} & -0.002 & {$[0.001]$} \\
Date squared & 0.007 & {$[0.025]$} & 0.006 & {$[0.025]$} & 0.007 & {$[0.025]$} \\
Constant & 37.483 & {$[9.341]^{* *}$} & 37.442 & {$[9.335]^{* *}$} & 37.614 & {$[9.356]^{* *}$} \\
\hline Observations & & 77,798 & & 77,798 & & 77,798 \\
Number of subjects & & 6,258 & & 6,258 & & 6,258 \\
\hline
\end{tabular}

Note: $* * 1 \%, * 5 \%$ significance.

Next, the impact of peer effect in terms of a newcomer's relative position in the new team, specifically, the difference in the impact of the peer effect between a relatively superior and an inferior newcomer, was investigated. This also examined the superstar effects and spillover models, such as the shining light and bad apple models. The average of personal best records for each team was calculated, and then the above average dummy, which takes 1 if the newcomer's best at the time newcomer dummy is zero, was rejected $(\mathrm{F}(1,278)=15.81, \mathrm{p}<.001)$. 
of transfer is faster than the team average, was created. A regression model with the cross-term between above average and After transfer dummies was adopted. For example, in the shining light model, this cross-term was expected to be significantly positive. As shown in Table 7, the coefficient of the cross-term is not significant. Then, the sample was divided according to whether the newcomer was above or below the team average to test specification (2). The findings showed that the coefficient of the after-transfer dummy is negatively significant only when the newcomer is faster than the team average in specification (1). However, the cross-term between After and fast newcomer, which takes 1 if the newcomer is faster than the swimmer, is significantly negative in both samples. The findings indicate that the important determinants for the effectiveness of peers is whether the newcomer is faster than them and not faster than the team average. However, there is a possibility that a swimmer could be aware of a newcomer whose age or gender is the same as his/her but does not mind the one whose characteristics are different from him/her. Therefore, an analysis was also performed on a newcomer's relative performance against the team average, as is shown in Table 7. Table 8 shows that similar results were obtained using the newcomer's relative performance against those of similar school age and gender as the newcomer was used. A newcomer's relative performance in the team is not influenced by a swimmer's performance, but a swimmer compares $\mathrm{him} /$ herself with the newcomer and is enhanced by a superior peer. 
Table 7: Results of the regression analysis with peer's relative positions

\begin{tabular}{|c|c|c|c|c|c|c|c|c|c|c|}
\hline & \multicolumn{2}{|c|}{$\begin{array}{l}\text { Effect of newcomers } \\
\text { who are faster than } \\
\text { their team average }\end{array}$} & \multicolumn{4}{|c|}{$\begin{array}{c}\text { Newcomers who are slower than their team } \\
\text { average }\end{array}$} & \multicolumn{4}{|c|}{ Newcomers who are faster than their team average } \\
\hline & Coef. & Std. Err & Coef. & Std. Err & Coef. & Std. Err & Coef. & Std. Err & Coef. & Std. Err \\
\hline After transfer dummy & -0.028 & [0.048] & -0.022 & [0.030] & 0.022 & [0.029] & -0.093 & {$[0.031]^{* *}$} & 0.146 & {$[0.035]^{* *}$} \\
\hline \multicolumn{11}{|l|}{ After dummy $*$} \\
\hline \multicolumn{10}{|l|}{ dummy } & \\
\hline \multicolumn{10}{|l|}{ Fast-newcomer dummy } & {$[0.052]^{* *}$} \\
\hline Own personal best & 0.638 & {$[0.015]^{* *}$} & 0.696 & {$[0.029]^{* *}$} & 0.696 & {$[0.028]^{* *}$} & 0.619 & {$[0.016]^{* *}$} & 0.613 & {$[0.016]^{* *}$} \\
\hline Date & -0.001 & {$[0.001]$} & -0.003 & {$[0.002]$} & -0.002 & {$[0.002]$} & -0.001 & {$[0.001]$} & -0.001 & {$[0.001]$} \\
\hline Date squared & 0.005 & {$[0.025]$} & 0.045 & [0.039] & 0.036 & {$[0.040]$} & -0.01 & {$[0.030]$} & -0.016 & {$[0.030]$} \\
\hline Constant & 37.058 & {$[9.323]^{* *}$} & 43.358 & {$[16.070]^{* *}$} & 40.748 & {$[16.475]^{*}$} & 34.201 & {$[10.846]^{* *}$} & 34.698 & {$[10.839]^{* *}$} \\
\hline Observations & & 77,798 & & 21,373 & & 21,353 & & 56,425 & & 56,378 \\
\hline Number of subjects & & 6,258 & & 1,637 & & 1,637 & & 4,687 & & 4,687 \\
\hline \multirow{2}{*}{\multicolumn{4}{|c|}{ H0: After dummy + After dummy $*$ Fast-newcomer dummy $=0$}} & \multicolumn{3}{|c|}{$\mathrm{F}(1,82)=6.75$} & & & \multicolumn{2}{|c|}{$\mathrm{F}(1,202)=27.24$} \\
\hline & & & & \multicolumn{3}{|c|}{ Prob $>F=0.011$} & & & \multicolumn{2}{|c|}{ Prob $>F=0.000$} \\
\hline
\end{tabular}

Note: $* * 1 \%, * 5 \%$ significance. 
Table 8: Results of the regression analysis with peer's relative positions

\begin{tabular}{|c|c|c|c|c|c|c|c|c|c|c|}
\hline & \multicolumn{2}{|c|}{$\begin{array}{l}\text { Effect of newcomers } \\
\text { who are faster than } \\
\text { their team average }\end{array}$} & \multicolumn{4}{|c|}{$\begin{array}{l}\text { Newcomers who are slower than } \\
\text { the team average of their age and gender group }\end{array}$} & \multicolumn{4}{|c|}{$\begin{array}{l}\text { Newcomers who are faster than } \\
\text { the team average of their age and gender group }\end{array}$} \\
\hline & Coef. & Std. Err & Coef. & Std. Err & Coef. & Std. Err & Coef. & Std. Err & Coef. & Std. Err \\
\hline After-transfer dummy & -0.001 & {$[0.037]$} & -0.015 & {$[0.031]$} & 0.044 & {$[0.028]$} & -0.117 & {$[0.036]^{* *}$} & 0.144 & {$[0.042]^{* *}$} \\
\hline \multicolumn{11}{|l|}{ After dummy * } \\
\hline $\begin{array}{l}\text { Above-average-newcomer } \\
\text { dummy }\end{array}$ & -0.128 & {$[0.065]$} & & & & & & & & \\
\hline $\begin{array}{l}\text { After dummy } * \\
\text { Fast-newcomer dummy }\end{array}$ & & & & & -0.165 & {$[0.062]^{* *}$} & & & -0.396 & {$[0.058]^{* *}$} \\
\hline Own personal best record & 0.638 & {$[0.015]^{* *}$} & 0.656 & {$[0.027]^{* *}$} & 0.654 & {$[0.027]^{* *}$} & 0.621 & {$[0.018]^{* *}$} & 0.614 & {$[0.017]^{* *}$} \\
\hline Date & -0.001 & {$[0.001]$} & -0.002 & {$[0.001]$} & -0.001 & {$[0.001]$} & -0.001 & {$[0.001]$} & -0.001 & {$[0.001]$} \\
\hline Date squared & 0.005 & {$[0.025]$} & 0.012 & {$[0.033]$} & 0.006 & {$[0.034]$} & 0.003 & {$[0.035]$} & -0.001 & {$[0.036]$} \\
\hline Constant & 37.047 & {$[9.392]^{* *}$} & 36.69 & {$[12.865]^{* *}$} & 35.102 & {$[13.163]^{* *}$} & 39.038 & {$[13.261]^{* *}$} & 40.42 & {$[13.083]^{* *}$} \\
\hline Observations & & 77,798 & & 34,714 & & 34,681 & & 43,084 & & 43,050 \\
\hline Number of subjects & & 6,258 & & 2,713 & & 2,713 & & 3,634 & & 3,634 \\
\hline \multicolumn{4}{|c|}{ H0: After dummy + After dummy $*$ Fast newcomer dummy $=0$} & \multicolumn{3}{|c|}{$\mathrm{F}(1,82)=6.75$} & \multicolumn{4}{|c|}{$\mathrm{F}(1,202)=27.24$} \\
\hline
\end{tabular}

Note: $* * 1 \%, * 5 \%$ significance. 


\section{Conclusions}

Using the transfer of newcomers to another team, the peer effect of teammates was examined. Specifically, this study investigated how a newcomer to a team influences the performance of the existing members of such team, and how the environment affects their performance. We found that the performance of an existing member is improved when a newcomer joins the swimming team. This effect is larger when the newcomer is superior to the other existing members of the team.

This study also revealed the relations between the characteristics of peers and the impact of peer effects. Peer effect from similar peers is assumed to be greater. However, based on our findings, the closeness of peer characteristics, such as gender, school age, and personal best record, between newcomers and existing members does not change the impact of peer effect. We found that the swimmers evaluated their peers based on their own performance and not on the team average. In other words, they are aware of their superior peers even though the latter are different from themselves. Establishing who exactly people compare themselves to is an important finding in relation to the study of peer effects.

This study also contributes to the discussion on the effectiveness of ability grouping, and provides evidence on how to optimally organize teams to achieve maximum productivity. Based on our findings, to maximize the performance of an organization, superior people must be distributed across all teams to improve everyone's performance.

The findings in this study differ from those found elsewhere that suggest an absence of peer effect. Zimmerman (2003) and Hayashi (2016) showed a lack of effect among roommates in terms of academic achievements. Although they did not examine the transfer of newcomers and their methods were quite different from ours, it is noteworthy that their examination of a similar situation produced opposite results. We consider that it would come from the characteristics of outputs. It is possible that academic achievements are also influenced by other social effect, for example the effect from their parents. In contrast, swimming data are free from other social effects because swimming can only be practiced at a swimming school, and students who come to a swimming school are sure to train. Similar results are suggested in other fields. For example, Zajonc (1965) suggested that the characteristics of tasks influence the direction of peer effects, indicating that there are positive peer effects in well-learned tasks, and negative peer effects in complicated tasks. This suggests further directions the study of peer effects could take in future research.

The limitations of this study include the lack of information in the database on coaches and their principles of guidance. The impact of teaching methods on peer effect could also be studied further. 


\section{References}

Azoulay, P., Graff Zivin, J. S., and Wang, J. 2010 "Superstar Extinction," The Quarterly Journal of Economics, 125 (2), pp. 549-589.

Brown, J. 2011 "Quitters Never Win: The (Adverse) Incentive Effects of Competing with Superstars," Journal of Political Economy 119, pp. 982-1013.

Burke, M. A. and Sass, T. R. 2013 "Classroom Peer Effects and Student Achievement," Journal of Labor Economics 31 (1), pp. 51-82.

Cooley, J. 2009 "Desegregation and the Achievement Gap: Do Diverse Peers Help?" WCER Working Paper. No. 2008-7.

Gneezy, U. and Rustichini, A. 2004, "Gender and Competition at a Young Age," American Economic Review 94 (2), pp. 377-381.

Gould, E. D. and Kaplan, T. R. 2011, "Learning Unethical Practices from a Co-worker: The Peer Effect of Jose Canseco,” Labour Economics 18, pp. 338-348.

Hayashi, R. 2016 "Peer Effects in Academic Performance," ISER Discussion Papers. No. 979.

Hoxby, C. M. and Weingarth, G. 2005 "Taking Race out of the Equation: School Reassignment and the Structure of Peer Effects," NBER Conference Paper.

Kato, T. and Shu, P. 2016 "Competition and Social Identity in the Workplace: Evidence from a Chinese Textile Firm,” Journal of Economic Behavior \& Organization, 131, pp. 37-50.

Manski, C. 1993 “Identification of Endogenous Social Effects: The Reflection Problem," Review of Economic Studies, 60 (3), 531-542.

Moser, P., Voena, A. and Waldinger, F. 2014 “German Jewish Émigrés and US Invention,” American Economic Review. 104 (10), pp. 3222-3255.

Recruit Life Style 2015 "Ranking of After-school Lessons for Children," http://www.recruit-lifestyle.co.jp/uploads/2015/09/RecruitLifestyle_keikotomanabu_20150925.pdf (accessed 6 Mar 2018, in Japanese).

Sacerdote, B. 2011 "Peer Effects in Education: How Might They Work, How Big Are They and How Much Do We Know Thus Far?" in Hanushek, E.A., et al. (eds.), Handbook of the Economics of Education, North-Holland, Amsterdam. pp. 250-273.

Waldinger, F. (2012) "Peer Effects in Science: Evidence from the Dismissal of Scientists in Nazi Germany," Review of Economic Studies, 79, pp. 838-861.

Yamane, S. and Hayashi, R. 2015 "Peer Effects among Swimmers," Scandinavian Journal of Economics, 117 (4), pp. 1230-1255.

Zajonc, R. B. 1965 “Social Facilitation,” Science 149 (3681), pp. 269-274.

Zimmerman, D. J. 2003, "Peer Effects in Academic Outcomes: Evidence from a Natural Experiment," Review of Economics and Statistics 85, pp. 9-23. 